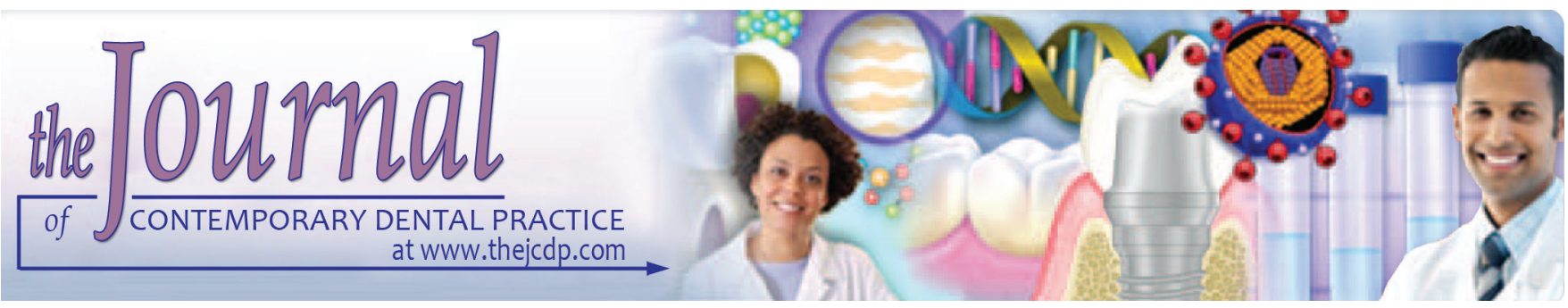

\title{
Cytological Changes in Normal Oral Mucosa of Individuals with Tobacco Habits: A Cytomorphometric Study
}

\author{
${ }^{1}$ Pavan Palakurthy, ${ }^{2}$ Pavan G Kulkarni, ${ }^{3}$ Rateesh K Nandan, ${ }^{4} \mathrm{~T}$ Madhusudan Rao \\ ${ }^{5} \mathrm{D}$ Shyam P Reddy, ${ }^{6}$ Keerthi Muddana
}

\begin{abstract}
Introduction: Oral cancer is one of the six most common cancers in the world, and globally more than $50 \%$ of head and neck cancers occur in Asia, remarkably in India. Overall, 200,000 cases of head and neck cancers occur each year in India, among which 80,000 are oral cancers. Epidemiological and clinical studies suggest a causative role of tobacco use in the evolution of oral potentially malignant and malignant disorders.
\end{abstract}

Aims and objectives: The aim of the study is to evaluate independently and compare the cytological effects of smoking, tobacco chewing, and smoking in conjunction with tobacco chewing on oral mucosa by cytomorphometric analysis.

Materials and methods: The study included a total of 120 individuals subdivided into four groups, each group with 30 individuals. Group I was tobacco smokers, group II tobacco chewers, and group III both tobacco smokers and chewers. Group IV comprised 30 individuals without tobacco habit. Smears were prepared from buccal mucosa of both the study and control groups using a cytobrush and stained using Papanicolaou staining. The cells were quantified using image analysis software.

Results: The results of the study showed alterations in the nuclear and cellular parameters in the study groups when compared with control groups and were statistically significant $(p<0.05)$.

Conclusion: The present study explains the significance of early identification of cellular changes in individuals with tobacco habits who require early intercession even without any visible

${ }^{1}$ Department of Oral Pathology, Government Dental College and Hospital, Hyderabad, Telangana, India

2,3,5,6 Department of Oral Pathology, Kamineni Institute of Dental Sciences, Narketpally, Telangana, India

${ }^{4}$ Department of Oral Pathology, KLR's Lenora Institute of Dental Sciences, Rajahmundry, Andhra Pradesh, India

Corresponding Author: Pavan Palakurthy, Department of Oral Pathology, Government Dental College and Hospital Hyderabad, Telangana, India, Phone: +919985321976, e-mail: pavanpalakurthy@gmail.com oral mucosal changes. The study emphasizes that exfoliative cytology and cytomorphometry aid as a valuable tool to evaluate the effect of tobacco on oral mucosa.

Clinical significance: Simple noninvasive techniques like exfoliative cytology can be employed as a chairside technique and in mass screening programs for identification of cellular changes in oral mucosa of individuals with tobacco habits. Thereby, it can be used as an early diagnostic tool for identification of potentially cancerous and cancerous lesions.

Keywords: Cytomorphometry, Exfoliative cytology, Oral cancer, Tobacco.

How to cite this article: Palakurthy P, Kulkarni PG, Nandan RK, Rao TM, Reddy DSP, Muddana K. Cytological Changes in Normal Oral Mucosa of Individuals with Tobacco Habits: A Cytomorphometric Study. J Contemp Dent Pract 2017; 18(8):722-727.

\section{Source of support: Nil}

Conflict of interest: None

\section{INTRODUCTION}

Geographically, there is a disparity in the occurrence of cancers of the head and neck worldwide among different countries and among various regions within a country. ${ }^{1}$ Oral cancer is the sixth most common malignancy and one of the major causes of death worldwide. It is a disease seen among middle-aged adults with a 5-year survival rate of $<50 \% .^{2}$ Globally, more than $50 \%$ of the head and neck cancers occur in Asia, remarkably in India. Overall, 200,000 cases of the head and neck cancers occur every year in India, among which more than $40 \%$ are oral cancers. In developing countries like India, most of the patients report at the time of advanced stage of disease, with which the survival rate is also reduced. ${ }^{3}$

Head and neck cancer in India has discrete distribution, risk factors, dietary habits, and personal and family history. ${ }^{3}$ Numerous contributory factors have been 
Cytological Changes in Normal Oral Mucosa of Individuals with Tobacco Habits

reported in the development of carcinoma of the oral cavity. Studies pertaining to the etiological factors in the evolution of oral potentially malignant and malignant disorders suggest tobacco as one of the factors for the disease. Usage of tobacco products can be in two forms, namely, smoking form as well as the smokeless tobacco chewing form. ${ }^{4}$ Smoking forms of tobacco include various kinds of cigarettes (manufactured, hand-rolled, filtered, unfiltered, and flavored), cigars, and pipes. ${ }^{5}$ Smokeless forms are used in combination with other ingredients, such as betel nut, areca nut, and slaked lime. ${ }^{6}$ Tobacco use is a primary cause of numerous oral lesions. It is a risk factor for oral cancer, oral cancer recurrence, adult periodontal diseases, and congenital defects, such as cleft lip and palate in children whose mothers smoke during pregnancy. The immune system response in persons with tobacco use is suppressed making them prone to oral infections, delays healing process, and promotes periodontal breakdown among diabetics. ${ }^{7}$

Oral cancer may appear as innocuous and asymptomatic lesions in the beginning stages. Symptomatic changes are seen in the advanced stages of tumor and the patients report to the clinician in this stage. ${ }^{8}$

Exfoliative cytology is a simple diagnostic technique that can be used for early detection of oral potentially malignant and malignant disorders. ${ }^{9}$ The quantitative parameters in exfoliative cytology can be used for identifying cellular changes and act as important aids in making the cytopathologic diagnosis. Quantitative parameter used in exfoliative cytology is morphometry. Nuclear size, cell size, nuclear-cytoplasmic ratio, nuclear shape, nuclear discontinuity, optical density, and nuclear texture are the quantitative parameters used in oral exfoliative cytology to confirm the diagnosis. ${ }^{10}$

The concept of cellular or nuclear alteration on exposure to different forms of tobacco can be best explained by reviewing the nature of cellular response to stimuli from the end products of different types of tobacco usage. ${ }^{1}$

Early diagnosis of the lesion is the key aspect in reducing the mortality associated with oral cancer. ${ }^{11}$

The purpose of the present study is to analyze the cytomorphology of cells from buccal mucosa of smokers, tobacco chewers, and people with combined habit of smoking and tobacco chewing using computerized image analysis software to assess the quantitative changes in oral mucosal keratinocytes for the early detection of premalignant and malignant changes.

\section{MATERIALS AND METHODS}

A total of 120 individuals were included in the study. They were divided into four groups; 30 were smokers, 30 were tobacco chewers, 30 were both smokers and
Table 1: Sample distribution for the study

\begin{tabular}{lll}
\hline Groups & Type of habit & Sample size \\
\hline I & Smokers & 30 \\
II & Tobacco chewers & 30 \\
III & Smokers and tobacco chewers & 30 \\
IV & Control group (without habit) & 30 \\
\hline
\end{tabular}

tobacco chewers, and 30 were control group without any habit (Table 1). The individuals with tobacco usage in either of the forms and who clinically did not show any visible changes in the oral mucosa were included in the study group. Individuals with a history of smoking or tobacco chewing for at least 5 years were included in this study. Individuals who smoke at least 10 cigarettes per day and had tobacco chewing of at least 10 packets per day were included in this study. Individuals with habitual alcohol intake, systemic diseases, oral potentially malignant disorders, and malignancy were excluded from the study.

Smears were prepared from the buccal mucosa of all the individuals using a cytobrush applying gentle pressure, till pinpoint bleeding was observed. The collected cells were smeared over the microscopic slide, fixed in alcohol, and stained using Papanicolaou stain. The stained smears were cytomorphometrically analyzed for the nuclear and cellular parameters using image analysis software Image-Pro insight version 8.0 at a magnification of $\times 40$ (Figs 1 and 2). The results were statistically analyzed using Statistical Package for the Social Sciences version 19.

The parameters included in the study were maximum diameter of the nucleus, minimum diameter of the nucleus, perimeter of nucleus, maximum diameter of cell, minimum diameter of cell, and perimeter of cell. The obtained results were statistically analyzed using analysis of variance (ANOVA) and Tukey's honest significant difference (HSD) for significance.

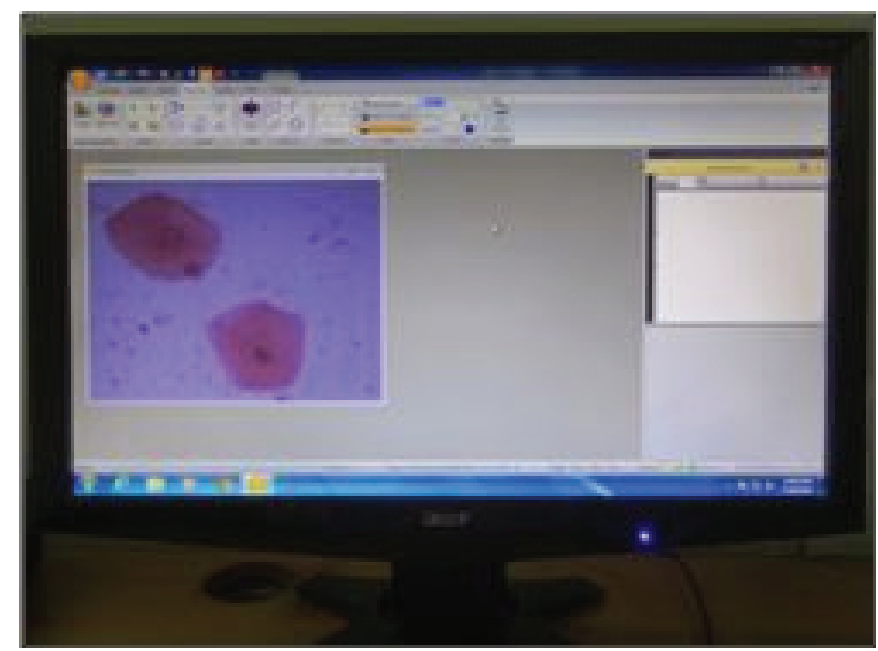

Fig. 1: Morphometry using image analysis software (Image-Pro Insight version 8) 


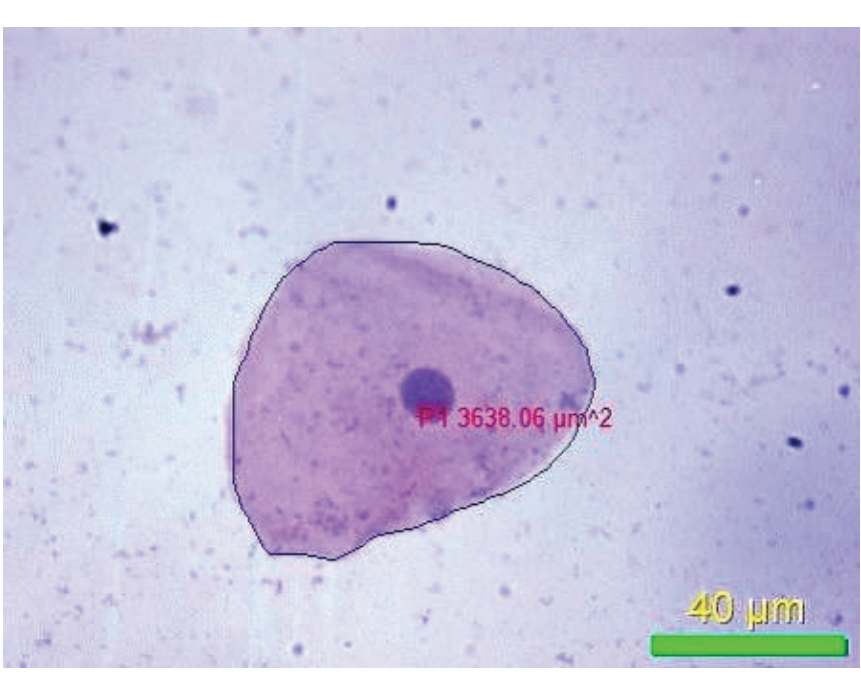

Fig. 2: Measurement of cell using image analysis software under $40 \times$ magnification

\section{RESULTS}

The mean and standard deviation (SD) obtained for different parameters in the study groups are shown in Table 2. The mean values of nuclear parameters were increased, whereas the cellular parameters were decreased in individuals with tobacco habits when compared with controls. The data were assessed for significance using one-way ANOVA and the obtained values were statistically significant $(p=0.000)$ (Table 3$)$. Multiple comparison Tukey's HSD was done between the study groups and the control group and in between the study groups (Tables 4 and 5). The categorized $p$ value was found to be statistically significant $(\mathrm{p}<0.05)$.

\section{DISCUSSION}

Tobacco use is one of the important causes of death and a leading public health problem worldwide. ${ }^{12}$ Tobacco
Table 2: Mean and SD for different parameters in study groups

\begin{tabular}{llll}
\hline Parameter & Groups & Mean \pm SD & $\begin{array}{l}\text { Standard error } \\
\text { of mean }\end{array}$ \\
\hline Maximum & I & $10.1449 \pm 1.28562$ & 0.05249 \\
diameter of & II & $10.4326 \pm 1.45601$ & 0.05944 \\
nucleus & III & $10.3929 \pm 1.33692$ & 0.05458 \\
& IV & $9.9362 \pm 1.85481$ & 0.07572 \\
Minimum & I & $6.7229 \pm 1.26179$ & 0.05151 \\
diameter of & II & $6.7382 \pm 1.41653$ & 0.05783 \\
nucleus & III & $6.7468 \pm 1.24766$ & 0.05094 \\
& IV & $5.9693 \pm 1.35427$ & 0.05529 \\
Perimeter of & I & $27.4885 \pm 3.68691$ & 0.15052 \\
nucleus & II & $28.7436 \pm 4.06835$ & 0.16609 \\
& III & $28.2412 \pm 3.15721$ & 0.12889 \\
Maximum & IV & $26.7817 \pm 4.33381$ & 0.17693 \\
diameter of & I & $55.3692 \pm 6.58736$ & 0.26893 \\
cell & II & $54.1468 \pm 7.42377$ & 0.30307 \\
& III & $52.9398 \pm 6.18954$ & 0.25269 \\
Minimum & IV & $57.2454 \pm 12.46956$ & 0.50907 \\
diameter of & I & $35.9301 \pm 5.05296$ & 0.20629 \\
cell & II & $35.1874 \pm 6.51937$ & 0.22490 \\
& III & $33.9061 \pm 5.50889$ & 0.26615 \\
Perimeter of & IV & $35.9278 \pm 7.48954$ & 0.30576 \\
cell & II & $152.8879 \pm 14.80025$ & 0.60422 \\
& III & $152.6645 \pm 19.84948$ & 0.81035 \\
& IV & $158.5000 \pm 29.83232$ & 1.21790 \\
\hline & & &
\end{tabular}

use is considered as one of the risk factors for oral cancer. Despite advances in surgery, radiotherapy, and chemotherapy, the 5-year survival rate of oral cancer patients has remained unchanged at approximately $50 \%$. This poor survival rate can be attributed mainly to the lack of early detection and treatment. ${ }^{11}$

Cellular morphology reflects the biologic behavior of the tissue of the host on one hand and genetic and molecular biology of the cells themselves on the other. The basic

Table 3: Statistical significance using one-way ANOVA for different parameters

\begin{tabular}{|c|c|c|c|c|c|c|}
\hline \multirow{4}{*}{$\begin{array}{l}\text { Parameter } \\
\text { Maximum diameter of the nucleus }\end{array}$} & & Sum of squares & Difference (df) & Mean square & Frequency (f) & Significance \\
\hline & Between groups & 96.649 & 3 & 32.216 & 14.318 & 0 \\
\hline & Within groups & 5391.298 & 2936 & 2.250 & & \\
\hline & Total & 5487.948 & 2399 & & & \\
\hline \multirow{3}{*}{ Minimum diameter of the nucleus } & Between groups & 264.722 & 3 & 88.241 & 50.500 & 0 \\
\hline & Within groups & 4186.630 & 2936 & 1.747 & & \\
\hline & Total & 4451.352 & 2399 & & & \\
\hline \multirow[t]{3}{*}{ Perimeter of the nucleus } & Between groups & 1330.919 & 3 & 443.640 & 30.131 & 0 \\
\hline & Within groups & 35277.952 & 2936 & 14.724 & & \\
\hline & Total & 36608.871 & 2399 & & & \\
\hline \multirow[t]{3}{*}{ Maximum diameter of the cell } & Between groups & 6076.858 & 3 & 2025.619 & 27.719 & 0 \\
\hline & Within groups & 175091.379 & 2936 & 73.077 & & \\
\hline & Total & 181168.236 & 2399 & & & \\
\hline \multirow[t]{3}{*}{ Minimum diameter of the cell } & Between groups & 1638.816 & 3 & 546.272 & 14.145 & 0 \\
\hline & Within groups & 92530.891 & 2936 & 38.619 & & \\
\hline & Total & 94169.707 & 2399 & & & \\
\hline \multirow[t]{3}{*}{ Perimeter of the cell } & Between groups & 36681.260 & 3 & 12227.087 & 29.152 & 0 \\
\hline & Within groups & 1004938.133 & 2936 & 419.423 & & \\
\hline & Total & 1041619.393 & 2399 & & & \\
\hline
\end{tabular}


Cytological Changes in Normal Oral Mucosa of Individuals with Tobacco Habits

Table 4: Least significant difference between nuclear parameters among different study groups (Tukey's HSD)

\begin{tabular}{|c|c|c|c|c|c|c|c|}
\hline \multirow[b]{2}{*}{ Dependent variable } & \multirow[b]{2}{*}{ (I) $G P$} & \multirow[b]{2}{*}{ (J) $G P$} & \multirow{2}{*}{$\begin{array}{l}\text { Mean difference } \\
(I-J)\end{array}$} & \multirow[b]{2}{*}{ Standard error } & \multirow[b]{2}{*}{ Significance } & \multicolumn{2}{|c|}{ 95\% confidence interval } \\
\hline & & & & & & Lower bound & Upper bound \\
\hline \multirow[t]{6}{*}{ Maximum diameter of the nucleus } & 1.00 & 2.00 & $-0.28763^{*}$ & 0.08660 & 0.001 & -0.4575 & -0.1178 \\
\hline & & 3.00 & $-2.4792^{*}$ & 0.08660 & 0.004 & -0.4177 & -0.0781 \\
\hline & & 4.00 & $-0.20877^{*}$ & 0.08660 & 0.016 & 0.0389 & 0.3786 \\
\hline & 2.00 & 3.00 & -0.03972 & 0.08660 & 0.647 & -0.1301 & 0.2095 \\
\hline & & 4.00 & $-0.49640^{*}$ & 0.08660 & 0 & 0.3266 & 0.6662 \\
\hline & 3.00 & 4.00 & $-0.45668^{*}$ & 0.08660 & 0 & 0.2869 & 0.6265 \\
\hline \multirow[t]{6}{*}{ Minimum diameter of nucleus } & 1.00 & 2.00 & -0.01530 & 0.07632 & 0.841 & -0.1650 & 0.1344 \\
\hline & & 3.00 & -0.02390 & 07632 & 0.754 & -0.1736 & 0.1258 \\
\hline & & 4.00 & $-0.75367^{*}$ & 07632 & 0 & 0.6040 & 0.9033 \\
\hline & 2.00 & 3.00 & -0.00860 & 07632 & 0.910 & -0.1583 & 0.1411 \\
\hline & & 4.00 & $-0.76897^{\star}$ & 07632 & 0 & 0.6193 & 0.9186 \\
\hline & 3.00 & 4.00 & $-0.77757^{\star}$ & 07632 & 0 & 0.6279 & 0.9272 \\
\hline \multirow[t]{6}{*}{ Perimeter of nucleus } & 1.00 & 2.00 & $-1.25508^{*}$ & 0.22154 & 0 & -1.6895 & -0.8207 \\
\hline & & 3.00 & -0.75272 & 0.22154 & 0.001 & -1.1871 & -0.3183 \\
\hline & & 4.00 & $-0.70678^{*}$ & 0.22154 & 0.001 & 0.2724 & 1.1412 \\
\hline & 2.00 & 3.00 & $-0.50237^{*}$ & 0.22154 & 0.023 & 0.0679 & 0.9368 \\
\hline & & 4.00 & $-1.96187^{*}$ & 0.22154 & 0 & 1.5274 & 2.3963 \\
\hline & 3.00 & 4.00 & $-1.45950^{*}$ & 0.22154 & 0 & 1.0251 & 1.8939 \\
\hline
\end{tabular}

${ }^{*}$ Mean difference is significant at the level of 0.05

Table 5: Least significant difference between cellular parameters among different study groups (Tukey's HSD)

\begin{tabular}{|c|c|c|c|c|c|c|c|}
\hline \multirow[b]{2}{*}{ Dependent variable } & \multirow[b]{2}{*}{ (I) $G P$} & \multirow[b]{2}{*}{ (J) $G P$} & \multirow{2}{*}{$\begin{array}{l}\text { Mean difference } \\
(I-J)\end{array}$} & \multirow[b]{2}{*}{ Standard error } & \multirow[b]{2}{*}{ Significance } & \multicolumn{2}{|c|}{ 95\% confidence interval } \\
\hline & & & & & & Lower bound & Upper bound \\
\hline \multirow[t]{6}{*}{ Maximum diameter of the cell } & 1.00 & 2.00 & $1.22250^{*}$ & 0.49355 & 0.013 & 0.2547 & 2.1903 \\
\hline & & 3.00 & $2.42942^{*}$ & 0.49355 & 0 & 1.4616 & 3.3972 \\
\hline & & 4.00 & $-1.87613^{*}$ & 0.49355 & 0 & -2.8440 & -0.9083 \\
\hline & 2.00 & 3.00 & $1.20692^{*}$ & 0.49355 & 0.015 & 0.2391 & 2.1747 \\
\hline & & 4.00 & $-3.09863^{*}$ & 0.49355 & 0 & -4.0665 & -2.1308 \\
\hline & 3.00 & 4.00 & $-4.30555^{*}$ & 0.49355 & 0 & -5.2734 & -3.3377 \\
\hline \multirow[t]{6}{*}{ Minimum diameter of cell } & 1.00 & 2.00 & $0.74263^{*}$ & 0.35879 & 0.039 & 0.0391 & 1.4462 \\
\hline & & 3.00 & $2.02400^{*}$ & 0.35879 & 0 & 1.3204 & 2.7276 \\
\hline & & 4.00 & 0.00228 & 0.35879 & 0.995 & -0.7013 & -0.7059 \\
\hline & 2.00 & 3.00 & $1.28137^{*}$ & 0.35879 & 0 & 0.5778 & 1.9849 \\
\hline & & 4.00 & $-0.74035^{*}$ & 0.35879 & 0.039 & -1.4439 & -0.0368 \\
\hline & 3.00 & 4.00 & $-2.02172^{*}$ & 0.35879 & 0 & -2.7253 & -1.3181 \\
\hline \multirow[t]{6}{*}{ Perimeter of cell } & 1.00 & 2.00 & 0.22338 & 1.18240 & 0.850 & -2.0953 & 2.5420 \\
\hline & & 3.00 & $5.43972^{*}$ & 1.18240 & 0 & 3.1211 & 7.7584 \\
\hline & & 4.00 & $-5.61210^{*}$ & 1.18240 & 0 & -7.9307 & -3.2935 \\
\hline & 2.00 & 3.00 & $5.21633^{*}$ & 1.18240 & 0 & 2.8977 & 7.5350 \\
\hline & & 4.00 & $-5.83548^{*}$ & 1.18240 & 0.039 & -8.1541 & -3.5168 \\
\hline & 3.00 & 4.00 & $-11.05182^{*}$ & 1.18240 & 0 & -13.3705 & -8.7332 \\
\hline
\end{tabular}

*Mean difference is significant at the level of 0.05

defect or the alteration of any cell begins at the molecular level triggering a series of reactions and, thereby, affecting the entire cell system and consequently its morphology. The general biological activity is reflected best in nucleus and functional activity is reflected in cytoplasm.

Exfoliative cytology is one such technique used to study the cells. It is a simple, noninvasive technique of obtaining cells for cytological analysis. In the present study, cytobrush was preferred over other instruments because of its ease of use and also because it provides good quality samples.
In the present study, there was increase in the maximum and minimum diameters of the nucleus in the study groups compared with control group. The carcinogens in the tobacco and also the trauma caused by the coarse nature of the contents in the chewing form of tobacco can lead to chronic inflammation and generation of reactive oxygen species (ROS), which can induce cell proliferation or apoptosis depending on the level of ROS production. During chronic exposure, these events can lead to preneoplastic lesions in the oral cavity and subsequently to malignancy. ${ }^{13}$ Ramesh et al, ${ }^{4}$ Hande and 
Chaudhary, ${ }_{1}^{1}$ Goregen et al, ${ }^{14}$ Acharya et al, ${ }_{15}^{15}$ and Babuta et $\mathrm{al}^{16}$ in their studies on tobacco have all reported similar findings in these parameters.

In the present study, there was significant increase in the mean value of perimeter of nucleus in the study groups in comparison with the control group (p-value $<0.05$ ). Cells of the oral epithelium undergo maturation as they move from the basal layer toward the surface. They increase in size as they migrate from basal to superficial layers. Increase in perimeter of nucleus in the study groups could be due to the reduced ability of the cytoplasm to mature with greatly increased activity of the nucleus leading to increase in the nuclear parameters because of the carcinogens present in tobacco. ${ }^{17}$ The present study was the first to use perimeter as the parameter to study the cytological changes.

In the present study, there was decrease in the maximum diameter of cell, minimum diameter of cell, and perimeter of cell in the study groups when compared with the control group. The decrease in maximum diameter of cell could be due to constant exposure to carcinogens from tobacco and mechanical injury from the contents of chewing form of tobacco resulting in chronic inflammation, generation of ROS, and depletion of protective enzymes in the cell. Carcinogens reduce the ability of the cytoplasm to mature so that there is a greater immaturity to the cytoplasm of the cell with greatly increased activity of the nucleus leading to decrease in cellular parameters. ${ }^{17}$ Hillman and Kissin ${ }^{18}$ reported an increase in cell size in smokers compared with nonsmokers. Drouilly cytologically analyzed the cells obtained by scraping the floor of the mouth in smokers and nonsmokers and did not observe significant differences in the types of epithelial cells obtained in smears.Most of the studies in the literature studied the effects of tobacco smoking or tobacco chewing on oral mucosal cells independently, and very few focused on the combined effects of both tobacco smoking and chewing on oral mucosal cells, the present study being one among them. Among the study groups, the alterations in parameters were more in individuals with combined habit of smoking and tobacco chewing when compared with individuals with either of the habits. ${ }^{19}$

The observation in the present study has revealed that there was increase in the nuclear parameters and a decrease in cellular parameters in the study groups when compared with the control group, thus stating that the cell morphology gets altered in individuals with tobacco habits even though the oral mucosa appears clinically normal. Increase in nuclear size and decrease in cellular size are seen in the early stages of transformation to dysplastic epithelium. ${ }^{4}$

In the present study, type of the cigarette used for smoking and also the duration of time for which the chewing tobacco is placed in the oral cavity were not considered. Studies done previously by Reddy and Shaik ${ }^{20}$ have shown that there is difference in the nicotine content of filtered and unfiltered types of cigarettes. The chewing form of tobacco contains less nicotine content than the smoking form, but the carcinogenic effect is more compared with the smoking form because of the duration of time for which it is kept in the oral cavity.

\section{CONCLUSION}

Studies pertaining to the etiological factors in the evolution of oral potentially malignant and malignant disorders suggest tobacco as one of the factors for the disease. The dysplastic epithelium shows variation in nuclear and cellular dimensions in comparison with normal epithelium. Early recognition of cellular changes and intervention are necessary in individuals with tobacco habits even in the absence of visible changes in the oral mucosa. The study emphasizes that exfoliative cytology and cytomorphometry aid as valuable tools to assess the influence of tobacco on oral mucosa. Further studies with larger sample size and considerations, such as type of cigarette (filtered or nonfiltered), nature of the chewing form (coarse or fine) of tobacco, and duration for which the product is placed in the mouth should be considered to evaluate the cytological effects of tobacco on oral mucosa.

\section{REFERENCES}

1. Hande AH, Chaudhary MS. Cytomorphometric analysis of buccal mucosa of tobacco chewers. Rom J Morphol Embryol 2010;51(3):527-532.

2. Abdelaziz MS, Osman TE. Detection of cytomorphological changes in oral mucosa among alcoholics and cigarette smokers. Oman Med J 2011 Sep;26(5):349-352.

3. Kulkarni MR. Head and neck cancer burden in India. Int J Head Neck Surg 2013 Jan;4(1):29-35.

4. Ramaesh T, Mendis BR, Ratnatunga N, Thattil RO. The effect of tobacco smoking and of betel chewing with tobacco on the buccal mucosa: a cytomorphometric analysis. J Oral Pathol Med 1999 Oct;28(9):385-388.

5. IARC Working Group on the Evaluation of Carcinogenic Risks to Humans. Smokeless tobacco and some tobacco-specific N-nitrosamines. IARC Monogr Eval Carcinog Risks Hum 2007;89:1-592.

6. Chadda RK, Sengupta SN. Tobacco use by Indian adolescence. Tob Induc Dis 2002 Jun;1(2):111-119.

7. Petersen PE. Tobacco and oral health - the role of the world health organization. Oral Health Prev Dent 2003 Dec;1(4):309-315.

8. Lewin F, Norell SE, Johansson H, Gustavsson P, Wennerberg J, Biörklund A, Rutqvist LE. Smoking tobacco, oral snuff, and alcohol in the etiology of squamous cell carcinoma of the head and neck: a population-based case-referent study in Sweden. Cancer 1998 Apr;82(7):1367-1375.

9. Wilson, GB.; Morrison, JH. Cytology. 2nd ed. New York: Rheinhold Publishing Corporation; 1966. p. 231-241. 
10. Kaugars GE, Brandt RB, Chan W, Carcaise-Edinboro P. Evaluation of risk factors in smokeless tobacco-associated oral lesions. Oral Surg Oral Med Oral Pathol 1991 Sep;72(3):326-331.

11. Mulki S, Shetty P, Pai P. Cytomorphological analysis in oral squamous cell carcinoma lesions and normal controls using rub and rinse technique. CCIJ 2014 Jan;3(1):38-42.

12. Bhimarasetty DM, Sreegiri S, Gopi S, Koyyana S. Perceptions of young male smokers in Visakhapatnam about tobacco use and control measures. Int J Res Dev Health 2013 Aug;1(3):129-135.

13. Nair $U$, Bartsch $H$, Nair J. Alert for an epidemic of oral cancer due to use of the betel quid substitutes gutkha and pan masala: a review of agents and causative mechanisms. Mutagenesis 2004 Jul;19(4):251-262.

14. Goregen M, Akgul HM, Gundogdu C. Cytomorphometric analysis of buccal mucosal cells in smokers. Turk J Med Sci 2011;41(2):205-210.

15. Acharya S, Tayaar SA, Khwaja T. Cytomorhometric analysis of the keratinocytes obtained from clinically normal buccal mucosa of chronic gutka chewers. J Cranio Maxillary Dis 2013 Jan;2(2):134-141.

16. Babuta S, Garg R, Mogra K, Dagal N. Cytomorphometrical analysis of exfoliated buccal mucosal cells: effect of smoking. Acta Med Int 2014 Jan-Jun;1(1):22-27.

17. Einstein TB, Sivapathasundharam B. Cytomorphometric analysis of the buccal mucosa of tobacco users. Indian J Dent Res 2005 Apr-Jun;16(2):42-46.

18. Hillman RW, Kissin B. Oral cytologic patterns in relation to smoking habits. Some epithelial, microfloral, and leukocytic characteristics. Oral Surg Oral Med Oral Pathol 1976 Sep;42(3):366-374.

19. Drouilly D. citologica exfoliativa en pacientes fumadores. Tesis para optar al titulo de Cirujano-Dentista. Universidad de Chile; 1986

20. Reddy SS, Shaik HA. Estimation of nicotine content in popular Indian brands of smoking and chewing tobacco products. Indian J Dent Res 2008 Apr-Jun;19(2):88-91. 